\title{
Prevention and Treatment of Radiation Induced Skin Damage in Breast Cancer
}

\author{
Rossella Di Franco ${ }^{1}$, Vincenzo Ravo ${ }^{2}$, Sara Falivene ${ }^{1 *}$, Angela Argenone ${ }^{2}$, Valentina Borzillo ${ }^{2}$, \\ Francesca Maria Giugliano ${ }^{2}$, Elena Sammarco ${ }^{3}$, Matteo Muto ${ }^{4}$, Salvatore Cappabianca ${ }^{1}$, Paolo Muto $^{2}$ \\ ${ }^{1}$ Radiation Oncology, Second University of Naples, Naples, Italy; ${ }^{2}$ Radiation Oncology Istituto Nazionale per lo Studio e la Cura dei \\ Tumori-Fondazione "Giovanni Pascale” IRCCS, Naples, Italy; ${ }^{3}$ U.O.S. of Dermatology P.O. Ascalesi, Naples, Italy; ${ }^{4}$ Radiation On- \\ cology Muto-Onlus Foundation of Naples, Casavatore, Naples, Italy. \\ Email: "sara.falivene@gmail.com
}

Received October $23^{\text {rd }}, 2013$; revised November $20^{\text {th }}, 2013$; accepted November $29^{\text {th }}, 2013$

Copyright (C) 2014 Rossella Di Franco et al. This is an open access article distributed under the Creative Commons Attribution License, which permits unrestricted use, distribution, and reproduction in any medium, provided the original work is properly cited. In accordance of the Creative Commons Attribution License all Copyrights @ 2014 are reserved for SCIRP and the owner of the intellectual property Rossella Di Franco et al. All Copyright (C) 2014 are guarded by law and by SCIRP as a guardian.

\section{ABSTRACT}

Introduction: Skin toxicity is a frequent side effect of radio and chemo-treatments in patients treated for breast cancer after conservative surgery. The aim of this paper is to report our experience in the management of skin toxicity evaluating radiotherapy planning and using preventive local aids. Materials and Methods: We have observed 300 patients undergoing radiotherapy. All received the prescription of a prophylactic moisturizing cream. Skin toxicity was valuated according to Acute Radiation Morbidity Scoring Criteria of the RTOG. Moreover, in a subgroup of 100 patients, we correlated the study of breast volume and features of treatment plans, with the addition of topic prophylactic treatment, using an oral therapy based on Resveratrol, Lycopene, Vitamin C and Anthocyanins $\left(\right.$ Ixor $^{\circledR}$ ). In another subgroup, 100 patients were subjected to corneometry assessing numerically skin hydration before, during and after radiotherapy. Results: In all patients, we related skin toxicity and the type of cream used. All patients completed the radiotherapy treatment, and G4 cutaneous toxicity was not observed in any of them. In patients treated with topic treatment and therapy based on Resveratrol, Lycopene, Vitamin C and Anthocyanins (Ixor ${ }^{\circledR}$ ), the protective effect of $\left(\right.$ Ixor $\left.^{\circledR}\right)$ is more detected in patients with PTV (Planning Target Volume) $<500 \mathrm{ml}$, when Dmax reaches values lower or equal to $107 \%$, but not exceeding $110 \%$ of the prescribed dose, and in patients undergoing adjuvant chemotherapy with anthracyclines and taxanes. The values of corneometry allow us to evaluate the moisturizing effect for products used, and identify cases of skin toxicity in a first phase. Conclusions: Our study confirms the value of moisturizers in the prevention and resolution of radiotherapy-induced skin damage. An instrumental assessment of skin hydration with corneometry can help the radiation oncologist to use strategies that prevent the onset of toxicity of high degree.

\section{KEYWORDS}

Skin Toxicity; Prevention and Treatment; Radiotherapy

\section{Introduction}

A great number of patients are submitted to radiotherapy (RT) treatment after conservative surgery with or without chemotherapy. An important clinical problem of these patients is the incidence of RT induced skin toxicity. It's related to the radiation technique, dose homogeneity, PTV receiving a dose greater than $100 \%$ of the pre-

\footnotetext{
${ }^{*}$ Corresponding author.
}

scribed dose [1]. In recent years, advanced radiation techniques have been developed, allowing a better homogeneity of dose and a relatively low risk of local toxicity [1]. The Intensity Modulated Radiation Therapy (IMRT) would reduce by $15 \%$ - 20\% moist desquamation in the irradiated skin, resulting in greater uniformity of dose and removing hot spots [2,3], even if IMRT has not yet the standard treatment for localized breast cancer. About the management of radiation-induced skin reac- 
tions, prophylaxis and an adequate symptomatic treatment are very interesting topics. The literature shows that the different grading of the acute toxicity can be related to treatment plan features (such as dose per fraction, total delivered dose, side and volume of the treated area, radiating energy), individual variations (such as age, chronic diseases, skin types, genetic predisposition) or to contribute of chemo-induced skin damage (sequential or concomitant cytotoxic chemotherapy) [4,5]. For this reason, it is difficult to estimate the incidence and the intensity of these adverse effects. Actually, skin care management guidelines during oncologic setting remain inconsistent. The prevention of acute effects on the skin and on the mucosae (cutaneous erythema, edema, pigmentation and/or mucositis) is an important aspect. Topical treatments (creams, pastes or sprays) are used on the radio-treated surfaces both during the RT that several months after the end of the therapy $[6,7]$.

Recently, there was a growing interest in the natural substances that may have a preventive or curative role against radio-induced dermatitis (Figure 1) [8,9].

Resveratrol (3,5,41-trihydroxystilbene) is a non-flavonoids phenol of red grapes that has an important antioxidant effect. The use of dietary supplements such as Resveratrol, Vitamin C and Anthocyanins (Ixor ${ }^{\circledR}$ ) fits into this perspective [10,11]. Similarly, the Lycopene more than other carotenoids, showed a great antioxidant and anti-free radical effect, while vitamin $\mathrm{C}$ and a Anthocyanin have a protective effect on skin cells $[12,13]$. All treatments remain linked to a subjective evaluation of the specialist involved (Dermatologist, Radiation Oncologist, Surgeon or Medical Oncologist), often without a multidisciplinary evaluation. From our point of view, multidisciplinary assessment of the patient and risk factors evaluation for the onset of cutaneous toxicity are necessary to plan the most appropriate strategies for each patient and to prevent toxicity. We think it's important to add to the subjective evaluation of the topical therapy, an instrumental measurement for the assessment of radioinduced skin damage. The purpose of our study in these years was to identify patients at high risk of radio-induced cutaneous toxicity evaluating the skin type, cor-

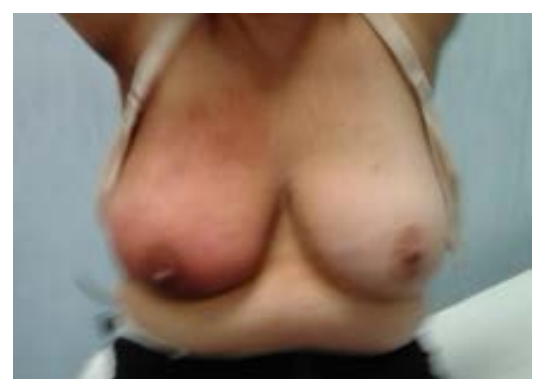

Figure 1. Radiodermatitis in patients treated for breast cancer. neometry and breast volume. In these patients, we analyzed the contribute of antioxidant substances based on Resveratrol, Vitamin C and Anthocyanins (Ixor ${ }^{\circledR}$ ) in addition to topical preventive therapy.

\section{Methods and Material}

Between February 2009 and December 2012, we observed a group of 300 patients all female, median age 56 years (range 28 - 80 years), with a pathologic diagnosis of breast cancer. Patients' characteristics are shown in Table 1.

All patients enrolled were treated with conservative surgery (quadrantectomy), surgical margins were free of disease, and adjuvant radiotherapy on whole breast without regional nodal irradiation (less than four nodes involved) according to Italian Association of Radiotherapy (AIRO) criteria [14]. All patients, after informed consent, were submitted to a Simulation CT-Scan, the three-dimensional treatment plan was set with the Pinnacle ${ }^{\circledR}$ TPS system, the target volumes were delineated according to the criteria of the International Commission on Radiation Units $[15,16]$. The Clinical Target Volume (CTV) was defined with the entire breast tissue palpable starting from $5 \mathrm{~mm}$ below the skin, the Planning Target Volume (PTV) was obtained with an expansion of the

Table 1. Characteristics of patients enrolled.

\begin{tabular}{|c|c|c|}
\hline Characteristic & & $\mathbf{N}$ patients \\
\hline Age & 28 - 80 (median 56) & 300 \\
\hline \multicolumn{3}{|l|}{ Surgery } \\
\hline QUAD & $100 \%$ & 300 \\
\hline LAD & $60 \%$ & 180 \\
\hline LNS & $40 \%$ & 120 \\
\hline \multicolumn{3}{|l|}{ Hystologic type } \\
\hline Ductal & $82 \%$ & 246 \\
\hline Lobular & $5 \%$ & 15 \\
\hline Others & $13 \%$ & 39 \\
\hline \multicolumn{3}{|l|}{ Chemiotherapy } \\
\hline Yes & $47 \%$ & 141 \\
\hline No & $53 \%$ & 159 \\
\hline \multicolumn{3}{|l|}{ Breast Volume } \\
\hline$>500 \mathrm{cc}$ & $75 \%$ & 225 \\
\hline$\leq 500 \mathrm{cC}$ & $25 \%$ & 75 \\
\hline \multicolumn{3}{|l|}{ Breast(max dose) } \\
\hline$\leq 107 \%$ & $20 \%$ & 60 \\
\hline$>107 \%<110 \%$ & $64 \%$ & 192 \\
\hline$\geq 110 \%$ & $16 \%$ & 48 \\
\hline \multicolumn{3}{|l|}{ Phototype } \\
\hline $\mathrm{I}$ & $0 \%$ & 0 \\
\hline II & $73 \%$ & 219 \\
\hline III & $27 \%$ & 81 \\
\hline IV & $0 \%$ & 0 \\
\hline \multicolumn{3}{|l|}{ Skin hydration } \\
\hline dry skin & $56 \%$ & 168 \\
\hline normal skin & $10 \%$ & 30 \\
\hline sensible skin & $34 \%$ & 102 \\
\hline
\end{tabular}


CTV margin of $10 \mathrm{~mm}$, except that towards the skin. Treatment plan was delivered using $6 \mathrm{MV}$ photons, until a dose of $50 \mathrm{~Gy}$ (2 Gy/fraction) to whole breast with tangential fields, and a sequential additional dose (boost) of $10 \mathrm{~Gy}$ (2 Gy/fraction) to the tumor bed [17].

The incidence of skin toxicity induced by radiation treatment, is usually related to the radiation technique, dose homogeneity, PTV dose (if more than $100 \%$ of the prescribed dose) [1].

All 300 patients received the prescription of a prophylactic moisturizing cream. They were instructed to apply cream topically every day ( 2 - 3 times/day) before (least 3 hours before) and after the radiotherapy treatment. Moreover, during radiotherapy it was prohibited to use other types of creams or perfumes on the irradiated skin. Patients were educated to carefully wash the area only with special oil soap and to wear loose clothes, preferably made of cotton.

In a subgroup of 100 patients we correlated the study of breast volume, with the addition of topic prophylactic treatment, using an oral therapy based on Resveratrol, Lycopene, Vitamin C and Anthocyanins (Ixor ${ }^{\circledR}$ ) prescribed at a dose of 2 tablets/day [18,19] from 10 days before the radiation treatment to 10 days after the treatment. The patients were divided into two different groups. In the first one, the control group (CG), we enrolled 51 patients to whom was prescribed only a topical prophylactic treatment. In the second group, Ixor-Group (IG), were enrolled 49 patients to whom, in addition to topic treatment, was prescribed an oral therapy based on Resveratrol, Lycopene, Vitamin C and Anthocyanins (Ixor ${ }^{\circledR}$ ). Even in this case we evaluated the relationship between toxicity and chemotherapy.

Subsequently, to evaluate the effect of inhomogeneities on dose toxicity, we related, in both groups, skin toxicity to PTV, but also to dosimetric factors, such as the breast volume receiving a dose equal or less than $107 \%$ of the prescribed dose, the one that received a dose greater than $107 \%$ and lower than $110 \%$ of the prescribed dose, and patients receiving a dose greater than $110 \%$ of the prescribed dose. All the doses $>107 \%$ are to be considered as single points in which there is a maximum dose.

In all cases, acute dermatitis related to radiation therapy was calculated among the patients presenting acute dermal toxicity of grade 2 or 3 (G2 + G3 RTOG). For two reports it has been calculated the absolute risk reduc- tion (ARR), relative risk (RR) and odds ratio (OR).

Another subgroup of 100 patients was subjected to corneometry assessing numerically skin hydration. The examination with Corneometer $\mathrm{CM}^{\circledR} 820$ is based on the measure of the ability of a dielectric medium, so any change in the dielectric constant caused by skin hydration shiftalters the measurement supplied by the condenser $[20,21]$. The corneometry provides an indirect measure of the barrier function. The values of skin hydration are considered normal if included in the range 60 - 90 a.u. In order to evaluate acute cutaneous toxicity, each patients was weekly submitted to skin examination [4] according to Acute Radiation Morbidity Scoring Criteria of the Radiation Therapy Oncology Group (RTOG) shown in Table 2 [16,22].

\section{Statistical Analysis}

In two reports, it has been calculated the absolute risk reduction (ARR), relative risk (RR) and odds ratio (OR). Another report was calculated percentages represented by histograms.

\section{Results}

In 100 patients we related skin toxicity and the type of cream used, randomizing the patients in 5 groups of 20 patients each one, and prescribing a different type of cream. All patients completed the radiotherapy, and G4 cutaneous toxicity was not observed in any of them. The results are in Figure 2 and in Table 3.

\begin{tabular}{cc}
\hline A & Pure vitamin E $\left(\right.$ Vea-lipoge $\left.^{\circledR}\right)$ \\
B & Omega-3,6,9 $\left(\right.$ Quinovit $\left.^{\circledR}\right)$ \\
C & Natural triglycerides-fitosterols $\left(\right.$ X-derit $\left.^{\circledR}\right)$ \\
D & Betaglucan, sodium hyaluronate $\left(\right.$ Neoviderm $\left.^{\circledR}\right)$ \\
E & Vitis vinifera A.s-I-M.t-O.dij $\left(\right.$ Ixoderm $\left.^{\circledR}\right)$ \\
\hline
\end{tabular}

The evaluation of these groups of patients showed that hydrating creams play a fundamental role in preventing radio-induced cutaneous damage. We have not recorded any toxicity of grade G4 and at the first follow-up visit, only $27 \%$ of the radiotherapy-treated patients still showed cutaneous toxicity, of grade G1. These preliminary results showed that the products of betaglucan sodium hyaluronate (Neoviderm ${ }^{\circledR}$ ) and Vitis vinifera A.s-I-

Table 2. ROTG scale used.

\begin{tabular}{cccc}
\hline Grade 0 & Grade 1 & Grade 2 & Grade 3 \\
\hline $\begin{array}{c}\text { No change over } \\
\text { baseline }\end{array}$ & $\begin{array}{c}\text { Follicular, faint or dull } \\
\text { erythema/epilation/dry } \\
\text { desquamation/decreased sweating }\end{array}$ & $\begin{array}{c}\text { Tender or bright erythema, } \\
\text { patchy moist desquamation/ } \\
\text { moderate edema }\end{array}$ & $\begin{array}{c}\text { Confluent, moist } \\
\text { desquamatiom other than } \\
\text { skin folds, pitting edema }\end{array}$ \\
\hline
\end{tabular}


Table 3. Number of patients in each group who received CT (anthracyclines, taxane), OT and related toxicity.

\begin{tabular}{|c|c|c|c|}
\hline Cream & Anthracycline & Taxane & Hormone \\
\hline \multirow{4}{*}{$\begin{array}{l}\text { Pure vitamin E } \\
\left(\text { Vea-lipogel }^{\circledR}\right)\end{array}$} & G0 3 & G0 1 & G0 8 \\
\hline & G1 1 & G1 1 & G1 4 \\
\hline & G2 2 & G2 2 & G2 3 \\
\hline & G3 0 & G3 0 & G3 0 \\
\hline \multirow{4}{*}{$\begin{array}{l}\text { Omega-3,6,9 } \\
\text { (Quinovit }^{\circledR} \text { ) }\end{array}$} & G0 0 & G0 0 & G07 \\
\hline & G1 2 & G1 1 & G1 6 \\
\hline & G2 2 & G2 2 & G2 4 \\
\hline & G3 0 & G3 1 & G3 0 \\
\hline \multirow{4}{*}{$\begin{array}{c}\text { Natural } \\
\text { triglyceridesfitosterols } \\
\left(\mathrm{X} \text {-derit }{ }^{\circledR}\right)\end{array}$} & G0 3 & G0 3 & G0 4 \\
\hline & G1 2 & G1 2 & G1 5 \\
\hline & G2 2 & G2 1 & G2 4 \\
\hline & G3 0 & G3 1 & G3 1 \\
\hline \multirow{4}{*}{$\begin{array}{c}\text { Betaglucan, } \\
\text { sodiumhyaluronate } \\
\left.\text { (Neoviderm }^{\circledR}\right)\end{array}$} & G0 3 & G0 3 & G0 9 \\
\hline & G1 2 & G1 1 & G1 4 \\
\hline & G2 1 & G2 0 & G2 2 \\
\hline & G3 0 & G3 0 & G3 0 \\
\hline \multirow{4}{*}{$\begin{array}{c}\text { Vitis } \\
\text { viniferaA.s-I-M.t-O.dij } \\
\left(\text { (Ixoderm }^{\circledR}\right)\end{array}$} & G0 1 & G0 0 & G0 10 \\
\hline & G1 3 & G1 3 & G1 3 \\
\hline & G2 0 & G2 0 & G2 1 \\
\hline & G3 0 & G3 0 & G3 0 \\
\hline
\end{tabular}

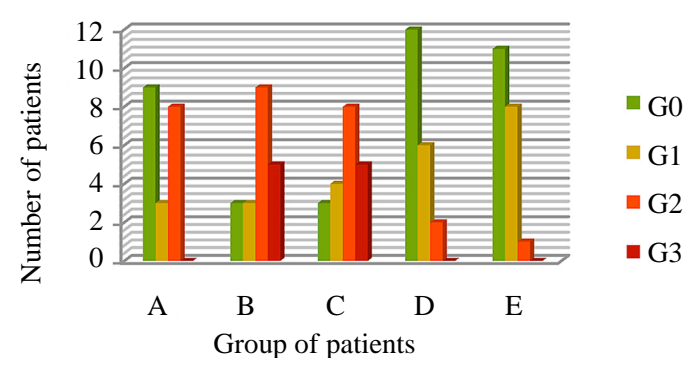

Figure 2. Skin Toxicity in 5 group of patients who used 5 different creams.

M.t-O.dij (Ixoderm ${ }^{\circledR}$ ) among those used, determined the best results to prevent cutaneous radio-induced damage. Moreover, from our results, neither taxanes and/or anthracyclines based chemotherapy nor hormonal therapy increase breast cutaneous toxicity induced by radiotherapy [23].

About the second subgroup correlating breast volume with the use of Ixor $^{\circledR}$, the first relationship that we made regarded acute skin toxicity, PTV and Chemotherapy (Table 4). When PTV was $>500 \mathrm{ml}$, Control-Group (CG) showed a high toxicity (G2 + G3) in 30\% of cases if compared with $25 \%$ of cases of Ixor $^{\circledR}$-Group (IG), with ARR of $5 \%$, RR of 0.83 and OR equal to 0.77 . When PTV was $<500 \mathrm{ml}$, the CG presented a skin toxicity(G2 + G3) in $18 \%$ of cases, versus $0 \%$ of IG, with ARR of $18 \%$, RR of 0.28 and OR equal to 0.23 . Results suggested a protective effect of Resveratrol, Lycopene, Vitamin C and Anthocyanins (Ixor ${ }^{\circledR}$ ) in both groups with ARR 25\%, RR of 0.22 and OR of 0.17 in patients who were not submitted to chemotherapy, and with ARR 7\%, RR of 0.74 and OR of 0.68 in patients who underwent chemo- therapy with Antracyclines and Taxanes.

Then we related skin toxicity to dosimetric values of each treatment plan (Table 5). In patients receiving a maximum dose less or equal to $107 \%$ of the prescribed, CG presented a toxicity G2 + G3 in $12.5 \%$ of cases, compared with $0 \%$ of IG with ARR $12.5 \%$, RR of 0.77 and OR of 0.73 . In patients who received a maximum dose higher than $107 \%$ and lower than $110 \%$ of the prescribed, CG presented a high skin toxicity (G2 + G3) in $35 \%$ of cases versus $21 \%$ of the IG, with ARR of $14 \%$, $\mathrm{RR}$ of 0.60 and OR of 0.50 . In patients receiving a maximum dose higher than $110 \%$ of the prescribed dose, the CG and the IG showed the same percentage of toxicity G2 + G3 with RR and OR of 1 .

When PTV was $>500 \mathrm{ml}$ we had an higher reduction of G2 + G3 skin toxicity percentage in IG if compared to CG, but this reduction is outstanding in patients with a PTV $<500 \mathrm{ml}$.

As shown in Figure 3 there is a significant prevalence of mild toxicity in the IG when Dmax reaches values lower or equal to $107 \%$ of the prescribed dose and when values of $110 \%$ of the dose are not exceeded. However when Dmax exceeds $110 \%$ of the dose there is no difference in toxicity, between the two treatment groups [24].

In the last year we assessed the contribution of corneometry in prediction of skin toxicity from radiation treatment. Corneometry values at starting point were between 40.5 (smallest median value) and 60.8 (highest median value) and at the end of treatment were between 45.7 (smallest median value) and 70.8 (highest median value). We evaluated the correlation between the values measured with the corneometry in the various groups (Table 6) and systemic therapies carried out by the patients, in particular for each type of therapy we evaluated the absolute risk reduction (ARR), relative risk (RR)and odds ratio (OR).

We have not found a clear correlation between systemic treatments and the values of corneometry, probably for the small number of patients examined. Regarding the correlation of the measurement with corneometry with

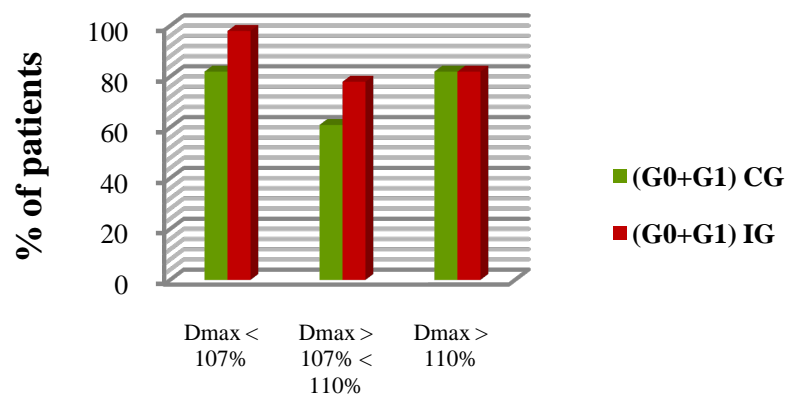

Figure 3. Relationship between the Dmax ( $<\mathbf{1 0 7 \%}$; $>\mathbf{1 0 7 \%}$ $<110 \% ;>110 \%)$ and the percentage of patients with mild toxicity (G0 + G1) in the two treatment groups. 
Table 4. Relationship between acute skin toxicity, PTV, CT.

\begin{tabular}{ccccccccc}
\hline & \multicolumn{2}{c}{ PTV $>\mathbf{5 0 0} \mathbf{~ m l}$} & \multicolumn{2}{c}{ PTV $<\mathbf{5 0 0} \mathbf{~ m l}$} & \multicolumn{2}{c}{ NO CT } & \multicolumn{2}{c}{ CT (Anthracyclines + Taxanes) } \\
\hline Tox (RTOG) & CG & IG & CG & IG & CG & IG & CG & IG \\
Grade (0 + 1) & $36(70 \%)$ & $37(75 \%)$ & $42(82 \%)$ & $49(100 \%)$ & $35(68 \%)$ & $46(93 \%)$ & $37(73 \%)$ & $39(80 \%)$ \\
Grade (2+ 3) & $15(30 \%)$ & $12(25 \%)$ & $9(18 \%)$ & $0(0 \%)$ & $16(32 \%)$ & $3(7 \%)$ & $14(27 \%)$ & $10(20 \%)$ \\
\hline
\end{tabular}

Table 5. Relationship between acute skin toxicity and dosimetric values.

\begin{tabular}{|c|c|c|c|c|c|c|}
\hline & \multicolumn{2}{|c|}{ Maximum dose $<107 \%$} & \multicolumn{2}{|c|}{$107 \%<$ Maximum dose $<110 \%$} & \multicolumn{2}{|c|}{ Maximum dose $>110 \%$} \\
\hline & CG & IG & CG & IG & CG & IG \\
\hline \multicolumn{7}{|l|}{ Tox (RTOG) } \\
\hline Grade $(0+1)$ & 45 (87.5\%) & $49(100 \%)$ & $33(65 \%)$ & 39 (79\%) & $44(86 \%)$ & $42(86 \%)$ \\
\hline Grade $(2+3)$ & $6(12.5 \%)$ & $0(0 \%)$ & $18(35 \%)$ & $10(21 \%)$ & $7(14 \%)$ & $7(14 \%)$ \\
\hline
\end{tabular}

Table 6. Topical treatment in five groups of patients.

\begin{tabular}{cc}
\hline & Topical Treatment \\
\hline Group A & Betaglucan, sodium hyaluronate $\left(\right.$ Neoviderm ${ }^{\circledR}$ ) \\
Group B & Vitis vinifera A. s-I-M.t-O.dij (Ixoderm ${ }^{\circledR}$ ) \\
Group C & Alga Atlantica and ethyl bisiminomethylguaicolo Manganese Cloruro (Radioskin $1^{\circledR}$ ) and metal esculetina, ginko biloba \\
Group D & and Aloe vera (Radioskin $2^{\circledR}$ ) \\
Group E & Natural triglycerides-fitosterols $\left(\right.$ Xderit $^{\circledR}$ ) \\
\hline
\end{tabular}

the breast volumes, we found breast volumes $>500 \mathrm{cc}$ both in groups $\mathrm{B}$ and $\mathrm{D}$. We can hypothesize a correlation between breast volumes of the group $\mathrm{D}$ and skin toxicity, but without a statistical significance. The values of corneometry however were similar in these groups, so we can't describe a direct correlation between the breast volumes, the corneometry values and the local toxicities. The results concerning the average value of corneometry and dermal toxicity (RTOG), obtained in the five groups, are shown in the following graphics (Figures 4 and 5).

The measurement with a corneometer confirmed the protective role of effective creams used routinely during radiation therapy of breast cancer. This allowed us to identify radiation induced dermatitis in a very early stage compared to only objective examination by allowing to treat early stage patients with a greater hydration or with steroid creams to intervene with early onset of erythema $[24,25]$.

\section{Discussion}

The radiotherapy-induced skin toxicity remains a major clinical problem that affects many patients with breast cancer undergoing adjuvant radiotherapy [26].

For women it's very important to be cured but body preservation is a priority too, so this is one important endpoint in modern RT. Many studies assessed the treatments and substances that can protect healthy organs from RT side effects.

Currently, there is no standard approach for the prevention and treatment of radio-induced skin lesions, although several studies have been published on the use of various kinds of topical agents [27,28].

In our study, we show that a good hydration of the skin before, during and after RT can have a positive effect on the skin tolerance of treatment. In our clinical practice we use to prescribe moisturizers to all patients with an indication for radiotherapy for breast cancer. In fact we believe that a preventive therapy of the skin side effects is more effective than a treatment of the local side effects once they appear. This approach shows significant effectiveness in reducing the onset of acute dermal toxicity. Acute radiodermatitis may affect the patients' quality of life and daily activities. In our experience we tested five different products in three hundred patients. The formulations of creams used showed good results. For all of them we received a satisfactory result. Most hydrating creams play a fundamental role in preventing radio-induced cutaneous damage. It is impossible for us to draw a conclusion about the question of what product is more active also because there are too many variables in the groups. In fact there are personal differences, of the phototypes, but also differences about the age of patients and the therapies that they received before, such as 


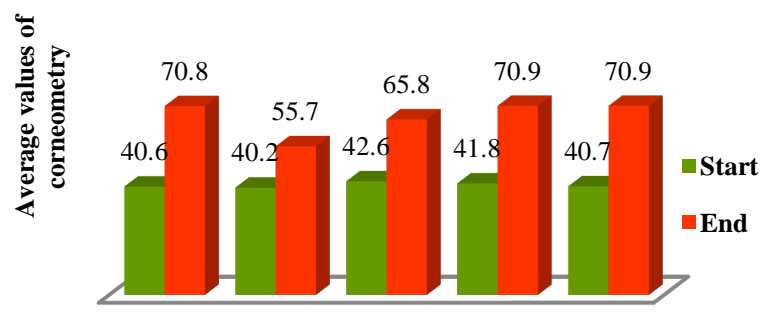

Group A Group B Group C Group D Group E

Figure 4. Mean values of corneometry at the start and the end of treatment in five groups of patients.

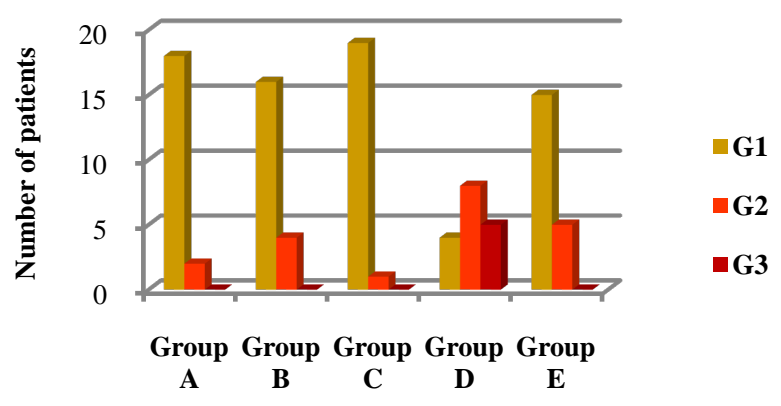

Figure 5. Skin toxicity observed in the five groups of patients undergoing corneometry and who used different creams.

chemotherapy, or hormonal therapy. The largest number of patients with a recorded skin toxicity, a month after RT, was related to the patient's biggest breast volumes, although we do not have a statistical significance.

Skin toxicity is influenced by whole breast volume and by the breast volume receiving dose-points $\geq 107 \%$ of the prescription. Chen et al., evaluated the effects of dosimetry on cutaneous prophylactic treatment and RT toxicity, demonstrating a correlation between skin toxicity and a dose $\geq 107 \%$ of the prescribed dose. They showed that the presence of a large volume receiving more than 53.9 Gy, was a predisposing factor to the onset of radiotherapy-induced skin toxicity [29].

By a long time, it's known the preventing role of a diet rich in antioxidants with regard to pathological conditions such as cancer, atherosclerosis, stroke, neurodegenerative diseases, diabetes $[26,27,30]$.

Our experience is concordant with literature data on RT skin toxicity so we have evaluated in a prospective trial the radioprotective effect of natural substances such as Resveratrol present in red grapes, the Lycopene, a carotenoid that has a high antioxidant capacity and anti free-radical action, and Vitamin C and Anthocyanins, contained in the red orange. Our study focuses on first step of the pathophysiology underlying the onset of radio-induced dermatitis, namely the excessive production of free radicals due to water radiolysis, responsible of cells damage on the basal layer of the epidermis and on endothelial cells. Substances with anti-inflammatory and antioxidant effects have been considered good candidates for protection against radiodermatitis, so we evaluated the potential protective role of Resveratrol, the Lycopene, Vitamin C and Anthocyanins (Ixor ${ }^{\circledR}$ ), and we found encouraging results in breasts with a volume lower than $500 \mathrm{ml}$ and in those who receive a radiation dose between $107 \%$ and $110 \%$ of the prescribed dose. The probability to record some "hot spots" in a treatment planning, with points in the PTV receiving doses $>107 \%$, is particularly high in patients with breasts $>500$ cc. Probably the toxicity linked to these dose uncertainties, sometimes inevitable, can't be avoided by any concomitant medical treatment. In fact we found no difference in the side effects of pts treated with this planning-dose characteristics. But in patients with a conventional dose distribution was found an advantage in the Ixor ${ }^{\circledR}$ group. Moreover the use of chemotherapy, alone or in combination, is inevitably linked to some adverse events that include dermal toxicity, especially with regard to the pattern with Anthracyclines and Taxanes [26]. Also in these patients the patients using Ixor $^{\circledR}$ had a better local result if compared to the control group. In our study we focused our interest also on this aspect, demonstrating a protective value of Resveratrol, Lycopene, Vitamin C and Anthocyanins $\left(\mathrm{Ixor}^{\circledR}\right.$ ) in patients undergoing chemotherapy with Anthracyclines and Taxanes.

Certainly the creation of a multidisciplinary team has allowed to identify cases of skin toxicity in a first phase and to determine the appropriate treatment to prevent the onset of dermatitis of high level. The skin side effects evaluation during and after RT is a normally clinical practice and it represents a subjective point of view of the phenomenon. In our study, we have combined clinical examination with corneometry. Although it is a measure of the water content of the skin, it is only an indirect measure of barrier function. However, there is a good relationship between numeric value and the extent of hydration under various physiological and pathological phenomena. Since water loss through the skin normally occurs by passive diffusion through the epidermis, smaller values indicate greater water loss and are consistent with increased damage of the barrier function of the stratum corneum $[28,31]$. With this technique, we will try to give an objective measurement of the skin side effects of radiotherapy in patients treated for breast cancer.

\section{Conclusion}

The management of skin toxicity in patients treated with RT for adjuvant breast cancer requires careful evaluation of the patient. It is necessary to evaluate the exposure to cytotoxic agents such as chemotherapy, the skin type, but also the state of skin hydration. They had to be considered the breast volume that may indicate protective supplements like resveratrol. In particular, patients who 
have a phototype I - III, which have a skin at risk valuated with the corneometry, a breast volume $>500 \mathrm{cc}$, benefit from protective factors and greater hydration to prevent cutaneous toxicity. Our study confirms the value of moisturizers in the prevention and resolution of radiotherapy-induced skin damage. An instrumental assessment of skin hydration with corneometry can help the radiation oncologist to use strategies that prevent the onset of toxicity of high degree.

\section{Acknowledgements}

Acknowledgments to Dr. Martina Samarelli for data collection.

\section{Disclosure of Interest}

There are no conflicts of interest to declare.

\section{REFERENCES}

[1] S. H. Moon, K. H. Shin, T. H. Kim, M. Yoon, S. Park, D. H. Lee, J. W. Kim, D. W. Kim, S. Y. Ark and K. H. Cho, "Dosimetric Comparison of Four Different External Beam Partial Breast Irradiation Techniques: Three-Dimensional Conformal Radiotherapy, Intensity-Modulated Radiotherapy, Helical Tomotherapy, and Proton Beam Therapy,” Radiotherapy \& Oncology, Vol. 90, No. 1, 2009, pp. 6673. http://dx.doi.org/10.1016/j.radonc.2008.09.027

[2] J. P. Pignol, I. Olivotto, E. Rakovitch, S. Gardner, K. Sixel, W. Beckham, T. T. Vu, P. Truong, I. Ackermaan and L. Paszat, “A Multicenter Randomized Trial of Breast Intensity-Modulated Radiation Therapy to Reduce Acute Radiation Dermatitis,” Journal of Clinical Oncology, Vol. 26, No. 13, 2008, pp. 2085-2092. http://dx.doi.org/10.1200/JCO.2007.15.2488

[3] A. G. Morganti, S. Cilla, V. Valentini, C. Digesù, G. Macchia, F. Deodato, G. Ferrandina, M. G. Cece, M. Cirocco, G. Garganese, L. Di Lullo, D. Traficante, F. Scarabeo, S. Panunzi, A. De Gaetano, G. Sallustio, N. Cellini, A. Piermattei and G. Scambia, "Phase I-II Studies on Accelerated IMRT in Breast Carcinoma: Tecnical Comparison and Acute Toxicity in 332 Patients," Radiotherapy \& Oncology, Vol. 90, No. 1, 2009, pp. 86-92. http://dx.doi.org/10.1016/j.radonc.2008.10.017

[4] S. Tucker, I. Turesson and H. Thames, "Evidence of Individual Differences in the Radiosensitivity of Human Skin,” European Journal of Cancer, Vol. 28A, 1992, pp. 1782-1791.

[5] D. Porock, L. Krisjanson, S. Nikoletti, F. Cameron and P. Pedler, "Predicting the Severity of Radiation Skin Reactions in Women with Breast Cancer," Oncology Nursing Forum, Vol. 25, 1998, pp. 1019-1029.

[6] B. Dubray, S. Delanian and J. L. Lefaix, "Effects of Mammary Radiotherapy on Skin and Subcutaneous Tissues,” Cancer/Radiothérapie, Vol. 1, No. 6, 1997, pp. 744752. http://dx.doi.org/10.1016/S1278-3218(97)82951-4

[7] D. Serin, L. Aimard, S. Kirscher, Y. Brewer, C. FelixFaure, P. Vincent, B. Chauvet and F. Reboul, “Adjuvant
Combined Radiochemotherapy: A Feasibility Study of a New Strategy in Stages I and II,” Bulletin du Cancer, Vol. 84, 1997, pp. 247-253.

[8] J. F. Weiss and M. R. Landauer, "Protection against Ionizing Radiation by Antioxidant Nutrients and Phytochemicals,” Toxicology, Vol. 189, No. 1-2, 2003, pp. 1-20. http://dx.doi.org/10.1016/S0300-483X(03)00149-5

[9] Y. Z. Fang, S. Yang and G. Wu, "Free Radicals, Antioxidants, and Nutrition,” Nutrition, Vol. 18, No. 10, 2002, pp. 872-879. http://dx.doi.org/10.1016/S0899-9007(02)00916-4

[10] Y. C. Oh, O. H. Kang, J. G. Choi, H. S. Chae, Y. S. Lee, O. O. Brice, H. J. Jung, S. H. Hong, Y. M. Lee and D. Y. Kwon, "Anti-Inflammatory Effect of Resveratrol by Inhibition of IL-8 Production in LPS-Induced THP-1 Cells,” The American Journal of Chinese Medicine, Vol. 37, No. 6, 2009, pp. 1203-1214. http://dx.doi.org/10.1142/S0192415X09007600

[11] D. A. Benitez, M. A. Hermoso, E. Pozo-Guisado, P. M. Fernandez-Salguero and E. A. Castellon, "Regulation of Cell Survival by Resveratrol Involves Inhibition of NF Kappa B-Regulated Gene Expression in Prostate Cancer Cells,” Prostate, Vol. 69, No. 10, 2009, pp. 1045-1054. http://dx.doi.org/10.1002/pros.20953

[12] L. Bignotto, J. Rocha, B. Sepodes, M. Eduardo-Figueria, R. Pinto, M. Chaud, J. de Carvalho, H. Moreno Jr. and H. Mota-Filipe, “Anti-Inflammatory Effect of Lycopene on Carrageenan-Induced Paw Oedema and Hepatic Ischaemiareperfusion in the Rat," British Journal of Nutrition, Vol. 102, No. 1, 2009, pp. 126-133. http://dx.doi.org/10.1017/S0007114508137886

[13] C. Felgines, S. Talavera, O. Texier, C. Besson, V. Fogliano, J. L. Lamaison, L. Fauci, G. Galvano, C. Remesy and F. Galvano, "Absorption and Metabolism of Red Orange Juice Anthocyanins in Rats," British Journal of Nutrition, Vol. 95, No. 5, 2006, pp. 898-904. http://dx.doi.org/10.1079/BJN20061728

[14] Gruppo di Lavoro AIRO per la Patologia Mammaria, "La Radioterapia dei Tumori della Mammella-Indicazioni e Criteri Guida,” AIRO, Graft Prints, 2009.

[15] International Commission of Radiation Units and Measurements, "ICRU Report 50: Prescribing, Recording, and Reporting Photon Beam Therapy,” International Commission of Radiation Units and Measurements, Bethesda, 1993.

[16] J. D. Cox, J. Stetz and T. F. Pajak, "Toxicity Criteria of the Radiation Therapy Oncology Group (RTOG) and the European Organization for Research and Treatment of Cancer (EORTC)," International Journal of Radiation Oncology * Biology * Physics, Vol. 31, No. 5, 1995, pp. 1341-1346. http://dx.doi.org/10.1016/0360-3016(95)00060-C

[17] P. Poortmans, "A Bright Future for Radiotherapy in Breast Cancer,” Radiotherapy \& Oncology, Vol. 82, No. 3, 2007, pp. 243-246. http://dx.doi.org/10.1016/j.radonc.2007.02.003

[18] D. A. Benitez, M. A. Hermoso, E. Pozo-Guisado, P. M. Fernandez-Salguero and E. A. Castellon, "Regulation of Cell Survival by Resveratrol Involves Inhibition of NF 
Kappa B-Regulated Gene Expression in Prostate Cancer Cells,” Prostate, Vol. 69, No. 10, 2009, pp. 1045-1054. http://dx.doi.org/10.1002/pros.20953

[19] S. Reagan-Shaw, H. Mukhtar and N. Ahmad, "Resveratrol Imparts Photoprotection of Normal Cells and Enhances the Efficacy of Radiation Therapy in Cancer Cells," Photochemistry and Photobiology, Vol. 84, No. 2, 2008, pp. 415-421. http://dx.doi.org/10.1111/j.1751-1097.2007.00279.x

[20] T. B. Fitzpatrick, A. Z. Eisen, K. Wolff, I. M. Freedberg and K. F. Austen, "Dermatology in General Medicine," McGraw-Hill, 1993, pp. 1692-1695.

[21] U. Heinrich, U. Koop, M. C. Leneveu-Duchemin, K. Osterrieder, S. Bielfeldt, C. Chkarnat, J. Degwert, D. Hantschel, S. Jaspers, H. P. Nissen, M. Rohr, G. Schneider and H. Tronnier, "Multicentre Comparison of Skin Hydration in Terms of Physical-, Physiological- and Product-Dependent Parameters by the Capacitive Method (Corneometer CM 825)," International Journal of Cosmetic Science, Vol. 25, No. 1-2, 2003, pp. 45-51. http://dx.doi.org/10.1046/j.1467-2494.2003.00172.x

[22] J. F. Weiss and M. R. Landauer, "Protection against Ionizing Radiation by Antioxidant Nutrients and Phytochemicals,” Toxicology, Vol. 189, No. 1-2, 2003, pp. 1-20. http://dx.doi.org/10.1016/S0300-483X(03)00149-5

[23] V. Ravo, M. G. Calvanese, R. Di Franco, V. Crisci, P. Murino, R. Manzo, A. Morra, F. Cammarota and P. Muto, "Prevention of Cutaneous Damages Induced by Radiotherapy in Breast Cancer: An Institutional Experience,” Tumori, Vol. 97, 2011, pp. 750-754.

[24] R. Di Franco, M. G. Calvanese, P. Murino, R. Manzo, C. Guida, D. Di Gennaro, C. Anania and V. Ravo, "Skin Toxicity from External Beam Radiation Therapy in Breast Cancer Patients: Protective Effects of Resveratrol, Lycopene, Vitamin C and Amthocianin (Ixor ${ }^{\circledR}$ ), " Radiation Oncology, Vol. 7, 2012, p. 12. http://dx.doi.org/10.1186/1748-717X-7-12
[25] R. Di Franco, E. Sammarco, M. G. Calvanese, F. De Natale, S. Falivene, A. Di Lecce, F. M. Giugliano, P. Murino, R. Manzo, S. Cappabianca, P. Muto and V. Ravo, "Preventing the Acute Skin Side Effects in Patients Treated with Radiotherapy for Breast Cancer: The Use of Corneometry in Order to Evaluate the Protective Effect of Moisturizing Creams,” Radiation Oncology, Vol. 8, 2013, p. 57. http://dx.doi.org/10.1186/1748-717X-8-57

[26] O. Gozzo Tde, M. S. Panobianco, M. J. Clapis and A. de Almeida, "Dermatological Toxicity in Women with Breast Cancer Undergoing Chemotherapy Treatment," Revista Latino-Americana de Enfermagem, Vol. 18, No. 4, 2010, pp. 681-687.

[27] Y. Z. Fang, S. Yang and G. Wu, "Free Radicals, Antioxidants, and Nutrition,” Nutrition, Vol. 18, No. 10, 2002, pp. 872-879.

http://dx.doi.org/10.1016/S0899-9007(02)00916-4

[28] J. Pinnagoda, R. Tupker, P. J. Coenraads and J. P. Nater, "Mesaurement of Transepidermal Water Loss," In: J. Serup and G. B. E. Jemec, Eds., Nonivasive Methods and the Skin, CRC Press, Boca Raton, 1995, pp. 173-178.

[29] M.-F. Chen, W.-C. Chen, C.-H. Lai, C.-H. Hung, K.-C. Liu and Y.-H. Cheng, "Predictive Factors of RadiationInduced Skin Toxicity in Breast Cancer Patients,” BMC Cancer, Vol. 10, 2010, p. 508. http://dx.doi.org/10.1186/1471-2407-10-508

[30] M. Schmuth, M. A. Wimmer, S. Hofer, A. Sztankay, G. Weinlich, D. M. Linder, P. M. Elias, P. O. Fritsch and E. Fritsch, “Topical Corticosteroid Therapy for Acute Radiation Dermatitis: A Prospective, Randomized, DoubleBlind Study,” British Journal of Dermatology, Vol. 146, No. 6, 2002, pp. 983-991. http://dx.doi.org/10.1046/j.1365-2133.2002.04751.x

[31] C. W. Blichmann and J. Serup, “Assessment of Skin Moisture. Measurement of Electrical Conductance, Capacitance and Transepidermal Water Loss," Acta DermatoVenereologica, Vol. 68, 1998, pp. 284-290.

\author{
Abbreviations \\ PTV: Planning Target Volume; \\ RT: Radiotherapy; \\ IMRT: Intensity Modulated Radiation Therapy; \\ AIRO: Italian Association of Radiotherapy; \\ CTV: Clinical Target Volume; \\ CG: Control Group; \\ IG: Ixor-Group; \\ ARR: Absolute Risk Reduction; \\ RR: Relative Risk; \\ OR: Odds Ratio.
}

